JAN 131992

\title{
GLOW DISCHARGE INITIATION WITH ELECTRON GUN ASSIST
}

\author{
by \\ K.L. HOLTROP, G.L. JACKSON, \\ K.M. SCHAUBEL, A.G. KELLMAN
}

NOVEMBER 1991

\section{GENERAL ATOMICS}




\section{DISCLAIMER}

This report was prepared as an account of work sponsored by an agency of the United States Government. Neither the United States Government nor any agency thereof, nor any of their employees, maless any warranty, expreas or implied, or asaumes any legal liability or responsibility for the sccuracy, completeness, or usefulness of any information, apparatus, product, or proces disclosed, or represents that its use would not infringe privately owned rights. Reference herein to any specific commercial product, process, or service by trede name, trademark, manufacturer, or otherwise, does not necessarily constitute or imply its endorsement, recommendation, or favoring by the United States Government or any agency thereof. The views and opinions of authors expressed herein do not necesaarily state or reflect those of the United States Government or any agency
thereof. 


\title{
GLOW DISCHARGE INITIATION WITH ELECTRON GUN ASSIST
}

\author{
by \\ K.L. HOLTROP, G.L. JACKSON, \\ K.M. SCHAUBEL, A.G. KELLMAN
}

This is a preprint of a paper to be presented at the 14th Symposium on Fusion Engineering, September 30-October 3, 1991, San Diego, California, and to be printed in the Proceedings.

\author{
Work supported by \\ Department of Energy \\ Contract DE-AC03-89ER51114
}
GENERAL ATOMICS PROJECT 3466
NOVEMBER 1991

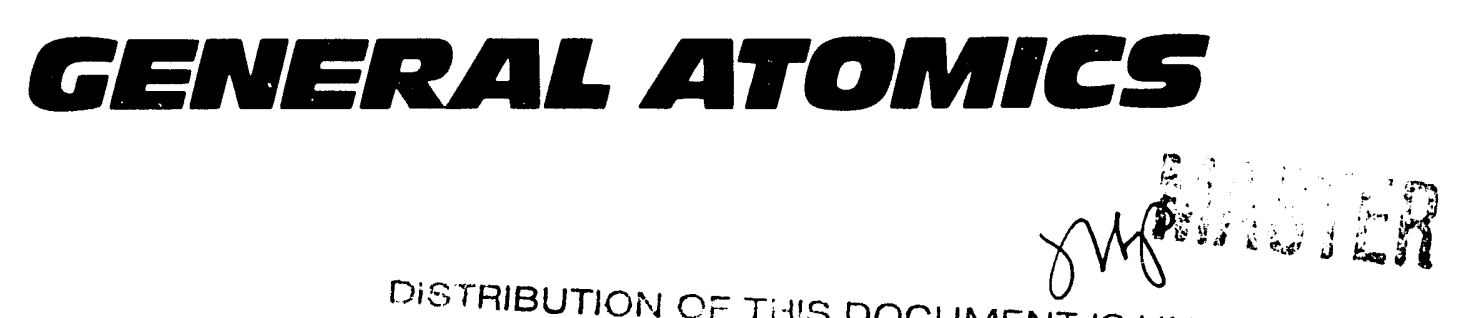




\title{
GLOW DISCHARGE INITIATION WITH ELECTRON GUN ASSIST
}

\author{
K.L. Holtrop, G.L. Jackson, K.M. Schaubel, A.G. Kellman \\ General Atomics \\ P.O. Box 85608
}

San Diego, California 92186-9784

Abstract: Helium glow discharge conditioning is used before every discharge in the DIII-D Tokamak to desorb hydrogen and low $\mathrm{Z}$ impurities from the graphite and Inconel plasma facing surfaces. However high gas pressure is required to initiate each glow discharge session and this requires frequent cycling of valves to protect pressure sensitive devices. To alleviate this mechanical fatigue an electron gun assisted glow system (EAG) is being installed on the DIII-D vessel to lower the initiation pressure. Through the injection of electrons the initiation pressure of the helium glow discharge has been lowered by a factor of 70 , bringing the initiation pressure within a factor of 2 of the minimum sustaining pressure of the glow discharge. This might also make possible pulsed glow conditioning which would allow a lower average pressure during glow conditioning reducing the heat load on proposed cryogenic pumping panels. Experimental results of the electron assist on He glow initiation and a scaling model for the electron gun assisted glow will be presented. The electron gun can also be used as a diagnostic. Without a glow discharge, the electron gun has been pulsed into the wall and the desorbed gas measured by a Residual Gas Analyzer. We are attempting to correlate the desorbed gas with recycling or vessel cleanliness.

\section{Introduction}

Helium glow discharge conditioning is use $\dot{\mathrm{d}}$ before every tokamak discharge in the DIII-D Tokamak to desorb hydrogen and low $Z$ impurities from the graphite and Inconel tiles and the Inconel wall which form the plasma facing surfaces. A pressure of $84 \mathrm{~m}$ Torr is needed to initiate a heliun glow discharge, after which the glow normally operates in the 1-3 mTorr range.

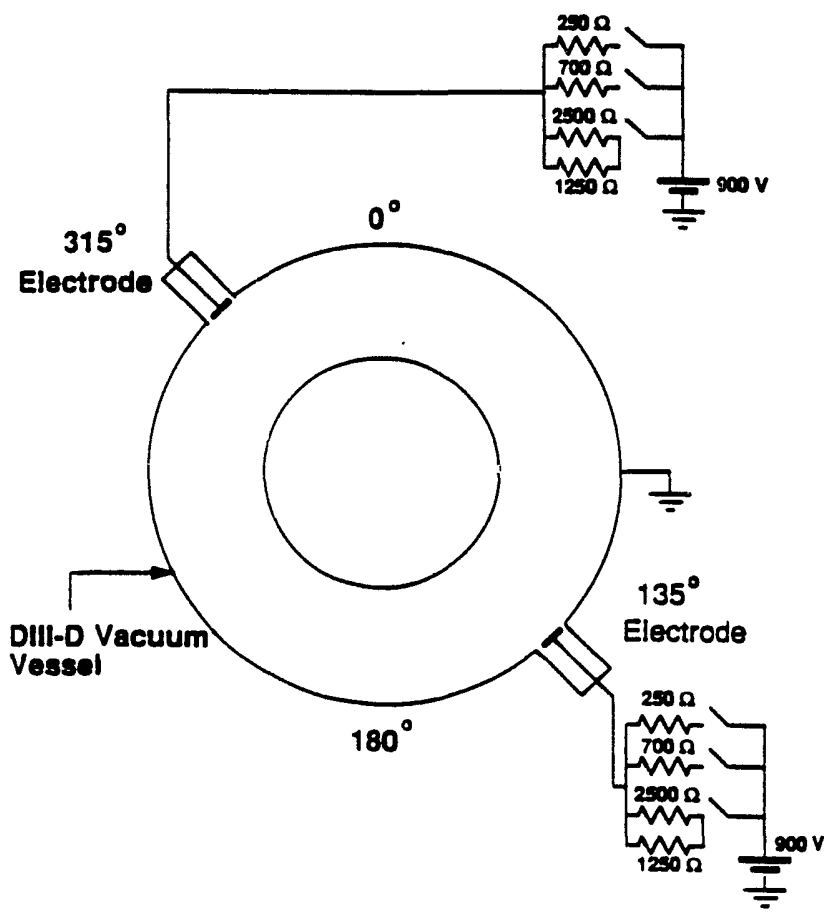

Fig. 1. Glow system schematic.

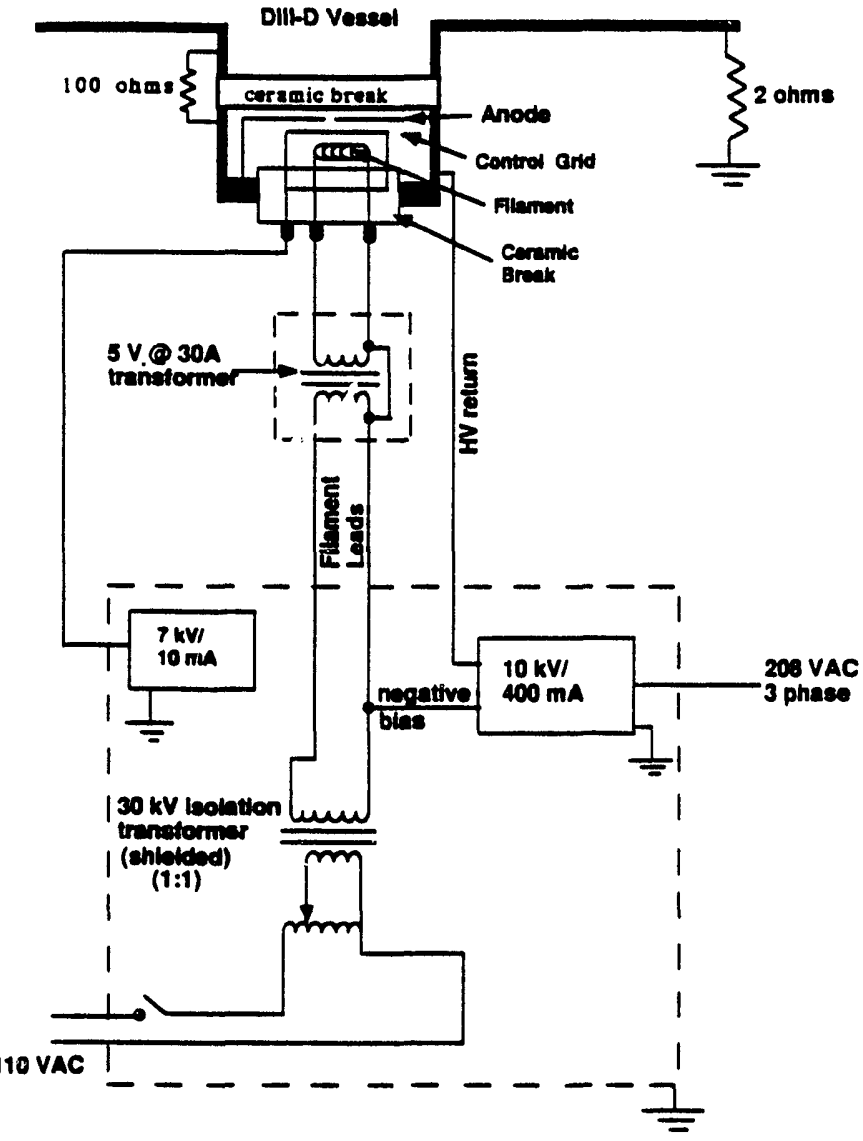

Fig. 2. Electron gun schematic.

Devices sensitive to the high initiation pressure have to be isolated during the startup phase causing excessive wear on bellows and valves. The frequent cycling of bellows has resulted in failures and vacuum leaks of the DIII-D vessel. In addition, at the high pressure needed for initiation the glow can penetrate into port appendages, desorb impurities in those areas, coat windows and produce arcing.

The Townsend ionization coefficient is lower for both $\mathrm{H}_{2}$ and $D_{2}$ than for He [1]. Taking advantage of this, $D_{2}$ is puffed in with the He until breakdown occurs. This lowers the initiation pressure to $\sim \mathbf{4 0} \mathrm{m}$ Torr. However, some of the deuterium is absorbed by the wall, and a longer glow session is required to remove it.

To further assist in lowering the initiation pressure an electron gun has been installed on the DIII-D vessel. With the electron gun a helium glow discharge was initiated at $1.2 \mathrm{~m}$ Torr, a factor of 70 lower than without the electron gun assist. This brings the initiation pressure within a factor of two of the minimum sustaining pressure. It should be possible to pulse the glow, lowering the avera'ze pressure and reducing the gas loading on cryogenic pump'ag panels. In addition to lowering the initiation pressure we are investigating the use of the electron gun as a diagnostic in determining wall conditions [2]. 


\section{DIII-D Glow Setup}

The DIII-D glow system consists of two graphite anodes $\left(0.025 \mathrm{~m}^{2}\right)$ biased positive with respect to the ressel wall (typically $900 \mathrm{~V}$ ) (Fig. 1.). A set of current limiting resistors allows for control of the current in the glow discharge. When glow is first initiated a large resistance is used to limit the current and prevent arcs. After the pressure has dropped the resistance is lowered to increase the current. The anodes are placed 180 degrees apart toroidaily and are recessed within ports on the outer wall with the front of the electrode flush with the vessel wall. The DIII-D system parameters fall on the Paschen curve such that breaikdown occurs to the far walls rather than in the port. The voltage at the anodes can be regulated from 200$600 \mathrm{~V}$ by adjusting the pressure in the versel. For an electrode voltage of $300 \mathrm{~V}$ on both electrodes, the total average current of $3.5 \mathrm{~A}$ corresponds to a wall current of $8 \mu \mathrm{A} / \mathrm{cm}^{2}$. The DIII-D vessel walls act as the cathode in the system collecting the positive ions.

\section{Electron Gun Setup}

Glow breakdown occurs when a sufficient number of charged particles exist between the anode and the cathode. To reach this level without increasing the neutral pressure an electron gun was used to inject electrons into the DIII-D vessel (Fig. 2.) The filament is negatively biased at approximately $5 \mathrm{kV}$ with respect to the anode which is at ground potential. Electrons are emitted from the filament, which is heated by a 28 A AC current, and accelerated toward the anode. Surrounding the filament is a control grid asembly. By biasing this assembly slightly more negative $(0.1 \mathrm{kV}-1.0 \mathrm{kV})$ than the filament, the electron beam emission eurrent and focus can be adjusted. The gun is electrically isolated from the vessel. Linking the vessel to the gun is a 100 ohm resistor used to measure the power leaving the filament. With $5 \mathrm{kV}$ on the filaments and $5.19 \mathrm{kV}$ on the control grid a total electron beam current of $50 \mathrm{~mA}$ is accelerated toward the anode, with $7 \mathrm{~mA}$ intercepted by the anode, a net emission current of $43 \mathrm{~mA}$ is obtained. The $5 \mathrm{kV}$ electrons pass through a focusing tube in the anode and stream

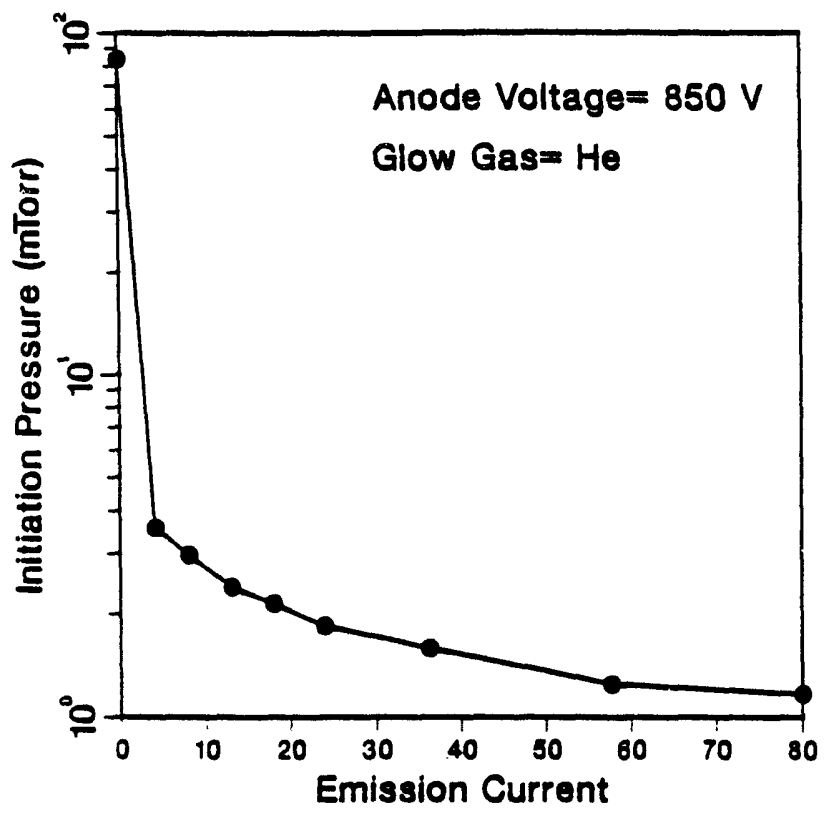

Fig. 3. Initiation pressure versus emission current for a He glow discharge. Even a small amount of emission current produces a large effect.

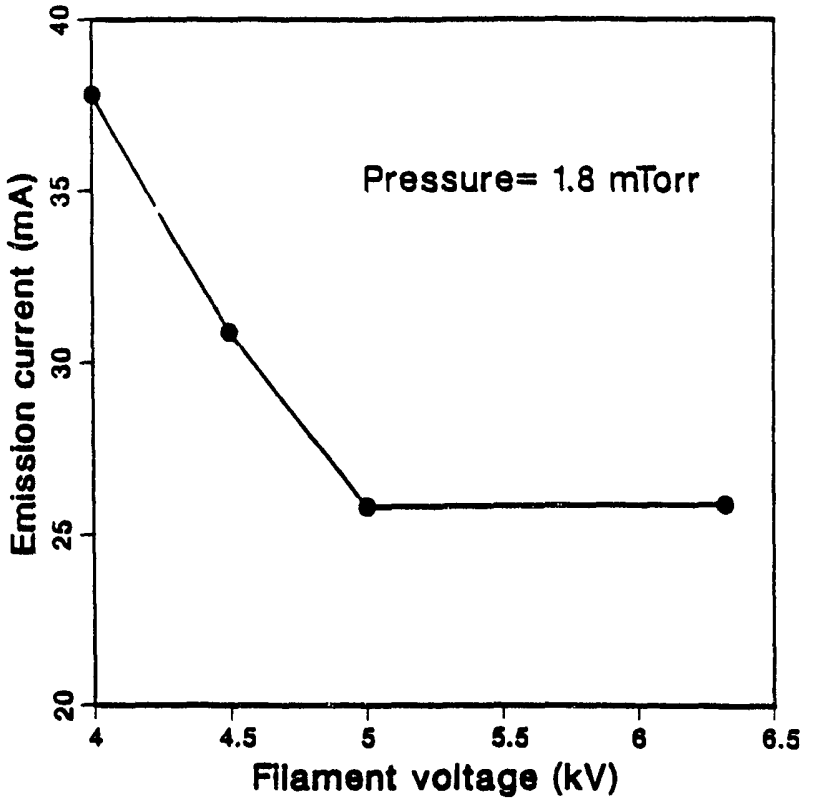

Fig. 4. The emiscion current needed for breakdown th $1.8 \mathrm{mT}$ Tor versus the energy of the electrons. A moderate decrease is seen before the curve appears to go asymptotic.

into the DIII-D vessel. The mean free path for ionization of He by $5 \mathrm{kV}$ electrons at $4 \mathrm{~m}$ Torr is $10 \mathrm{~m}$. Since the line of sight for the electrons in the DIII-D is $1 \mathrm{~m}$, very few molecules will be ionized by the high energy electrons. The high energy electrons strike the wall producing lower energy secondary electrons. It is these low energy secondary electrons which dominate the glow initiation.

\section{Results in DIII-D}

The electron gun was able to inject a current of $80 \mathrm{~mA}$ with energies up to $6.3 \mathrm{kV}$ into the vessel. With this the initiation pressure was lowered from 84 mTorr without the electron gun assist down to $1.4 \mathrm{~m}$ Torr (Fig. 3.). A large decrease in initiation pressure was seen for even a moderate initial increase in electron gun current. Further increases in current produced proportionately smaller decreases in initiation pressure.

Similar results were obtained for deuterium glow discharges. The initiation pressure dropped from 40 mTorr down to $0.8 \mathrm{~m}$ Torr with an injected electron current of $49 \mathrm{~mA}$.

The emission current needed for breakdown at $1.8 \mathrm{~m}$ Torr versus the energy of the injected electrons was measured for He glow (Fig. 4.). With increasing electron energy the emission current needed drops slightly before becoming constant. This may be explained by an increase in the number of secondary electrons produced per high energy electron impact with the DIII-D wall, reducing the amount of emission current needed for breakdown.

Increasing the electron gun current had no effect on the minimum sustaining energy (Fig. 5.).

No effect was seen on the reduction of the initiation pressure before and after the DIII-D vessel was boronized. 'This was surprising since it seemed likely that the boron coating would change the characteristics of the secondary emission.

\section{Pulsed Glom}

A primary motivation for the electron gun was to reduce the heat load on proposed cryogenic panels. In addition to 


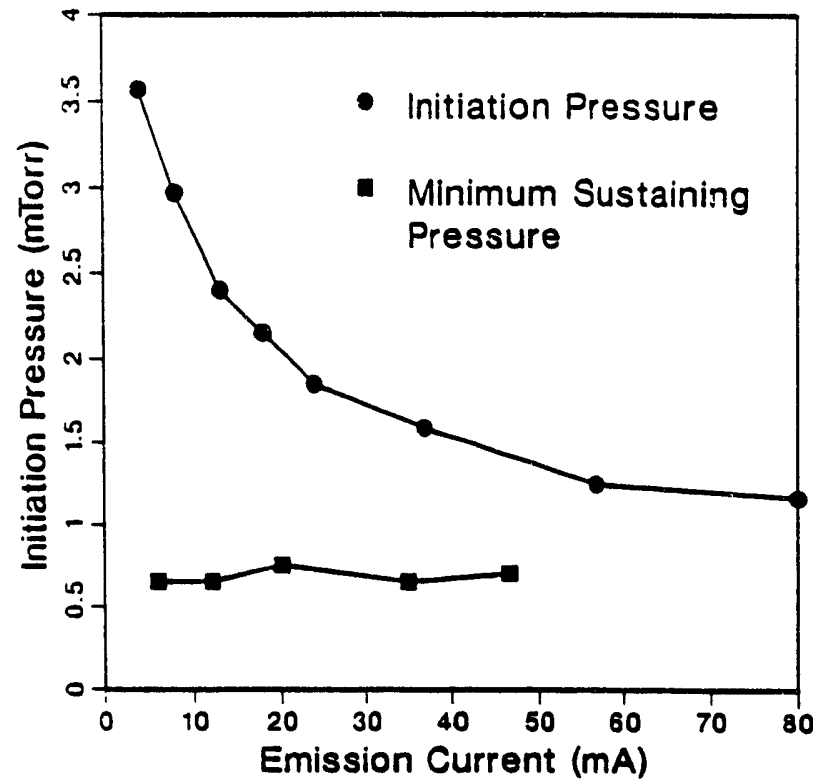

Fig. 5. The minimum sustaining pressure and the initiation prescure versus the electron gun emission current. The initiation pressure is well with the normal pressure range of the He glow discharge.

lowering the initiation pressure, the electron gun could also lower the heat load by allowing a pulsed glow dischrage which will lower the average pressure during a glow session. The gas flow to the glow would be turned off and constant machine pumping would decrease the pressure of the glow, lessening the heat load on the cryogenic pumps. It is likely that the glow would extinguish since the pressure would drop below the minimum sustaining pressure. The glow would then need to be reinitiated. With the electron gun assist, however, the pressure would not have to be raised 'sver the normal working pressure of the He glow discharge (normally 1.5-2.5 mTorr) (Fig. 5.). The average pressure for the He glow discharge session could be reduced.

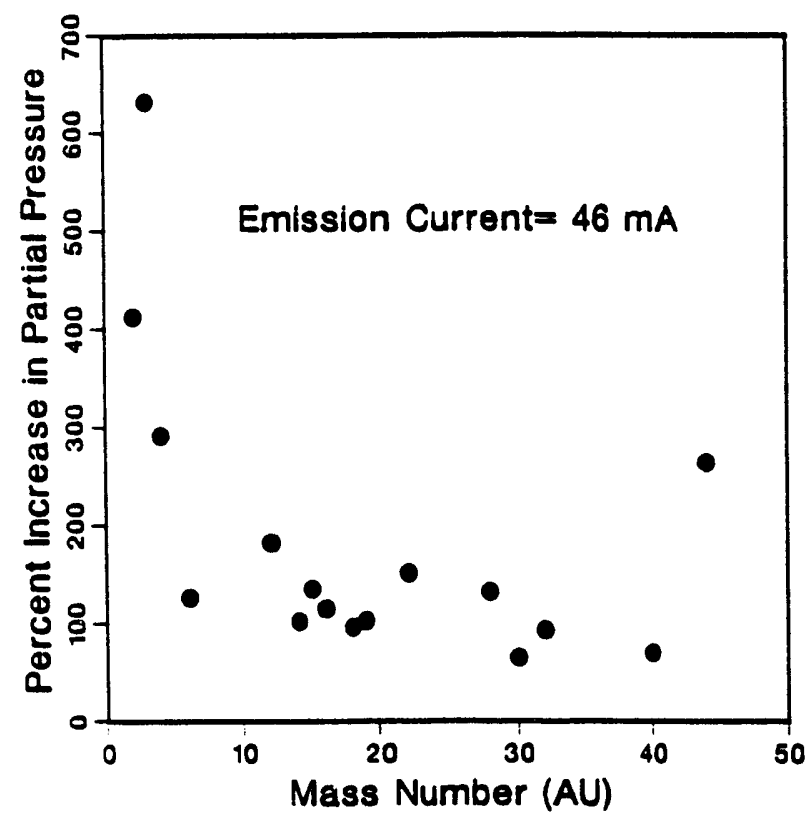

Fig. 6. The percent increase of various partial pressures for electron gun injection into the vessel walls without a glow discharge. The largest increases occur for Mase $2\left(\mathrm{H}_{2}\right)$ Mass 3 (HD), Mase $4\left(\mathrm{D}_{2}, \mathrm{He}\right)$, and mase $44\left(\mathrm{CO}_{2}\right)$.

\section{The Electron Gun as a Diagnostic}

Additional benefits of the electron gun include the use of the gun as a diagnostic. Without a glow discharge the electron gun can be pulsed into the wall and the desorbed gas measured by a Residual Gas Analyzer. It may be possible to correlate the desorbed gas with recycling and wall pumping during tokamak discharges. The gases showing the largest desorption are mass $2\left(\mathrm{H}_{2}\right)$, mass $3(\mathrm{HD})$, mass $4\left(\mathrm{He}, \mathrm{D}_{2}\right)$, and mass $44\left(\mathrm{CO}_{2}\right)$ (Fig. 6.). The partial pressures ranged from $3.5 \times 10^{-8}$ Torr for mass 2 down to $8.2 \times 10^{-11}$ Torr for mass 22 .

The amount of desorbed gas increases with electron gun current. The partial pressure of $D_{2}$ increases linearly with increasing electron gun current throughout the majority of the gun's range (Fig 7 .).

\section{Electron Gun Assisted Glow Scaling Model}

A small version of the electron gun was tested on a test chamber before a electron gun was designed and installed on

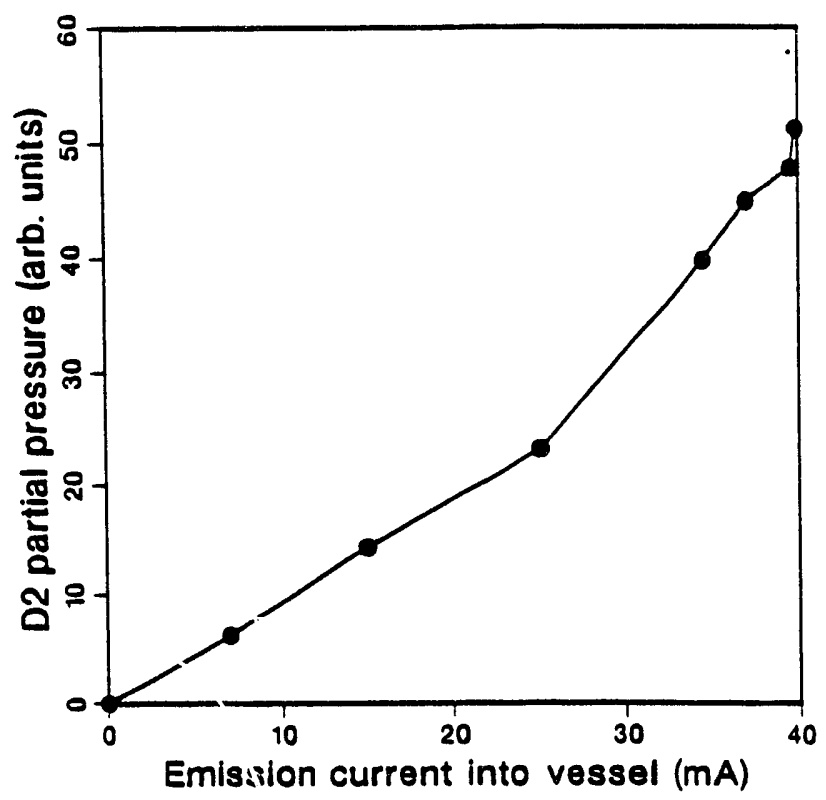

Fig. 7. The partial pressure of $D_{2}$ varies linearly with increising electron gun emission current.

the DIII-D vessel [3]. The protctype gun had emission currents up to $10 \mathrm{~mA}$ with energies on the order of $1.6 \mathrm{kV}$. It was able to reduce the :nitiation pressure in a small test chamber from $165 \mathrm{~m}$ Torr to $1.6 \mathrm{~m}$ Torr.

To determine the electron gun parameters needed for DIII-D, the following simplified model was developed in order to relate the chamber dimensions to the emission current.

The effect of the electron gun is to increase the electron density in the DIII-D tokamak to allow glow initiation at a lower pressure.

In the absence of an external source of electrons, glow initiation is described by Paschen's curves [4], where the initiation voltage is a function of $\mathrm{Pd}$, where $\mathrm{P}$ is the neutral density and $d$ is the ionizing path length. For this scaling model with an additional electron source we assume that breakdown is also a function of Pd. 
In our model, the electron density, $n_{e}$, (before glow initiation) is given by

$$
n_{e}=\frac{i_{e} L_{0} \gamma}{e V_{0 L} \sqrt{\frac{2 k T_{e}}{m_{e}}}}
$$

where $i_{e}$ is the electron emission current, $L_{0}$ is the longest dimension of the changer, $\gamma$ is the number of secondary electrons produced by a high energy electron impact with the wall, $V_{0 L}$ is the volume of the vessel, $k$ is the Boltzman constant, $T_{e}$ is the secondary electron temperature, and $m_{0}$ is the mass of an electron [3].

We assume that breakdown will occur at the same value of $\mathrm{Pd}$ for both in DIII-D and the test chamber if the electron density, $n_{e}$, is the same value for both. Hence from (Eq. 1), we obtain

$$
i_{e}^{\mathrm{DIII}-\mathrm{D}}=\frac{L_{0}^{\mathrm{lab}}}{L_{0}^{\mathrm{DIII}-\mathrm{D}}} \frac{V_{0 L}^{\mathrm{DIII}-\mathrm{D}}}{V_{0 L}^{\text {Lab }}} i_{e}^{\text {lab }} .
$$

Using this relationship we can predict the electron current required in DIII-D (shown as a dashed line in Fig. 8.). The actual results show good agreement with the predicted values.

\section{Conclusion}

An electron gun was installed on the DIII-D vessel with the result that the initiation pressure for helium glow was lowered by a factor of 70 from $84 \mathrm{~m}$ Torr to $1.2 \mathrm{~m}$ Torr. A similar result occurred for $D_{2}$ with the initiation pressure being lowered from $40 \mathrm{~m}$ Torr down to $0.8 \mathrm{~m}$ Torr. The electron gun had no effect on the minimum pressure needed to sustain the glow. A scaling model was developed showing the dependence on chamber dimensions and electron gun current. The EAG can be used as a diagnostic to study the wall conditions of the graphite tiles in the DIII-D ressel.

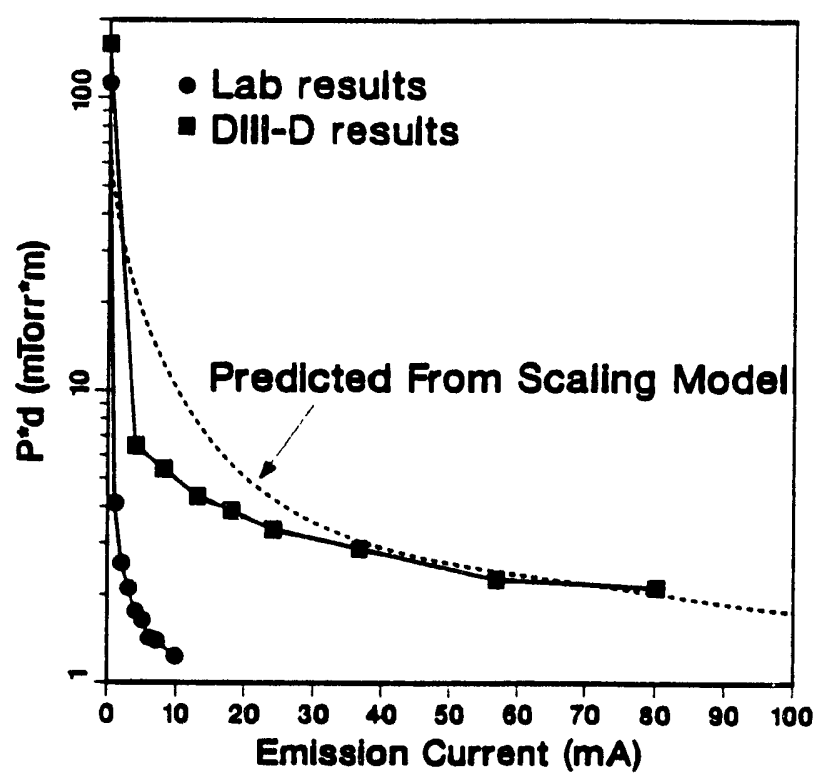

Fig. 8. The scaling model and the data from the small test chamber allowed for the prediction of Pd for the DIII-D vesel. The model shows good agreement with the actual results.

\section{Acknowledgment}

This work was sponsored by the U.S. Department of Energy under Contract No. DE-AC03-89ER51114.

\section{References}

[1] J.D. Cobine, Gaseous Conductors, Clarendon Press, Oxford, 1955.

[2] Y. Nakashims, et al., Journal of Nuclear Materials 162-164 (1989) 812-817.

[3] K.M. Schaubel, G.L. Jackson, General Atomics Report GA-A19809 (1989).

[4] A. ron Engel, Ionized Gases, Oxford University (1955). 

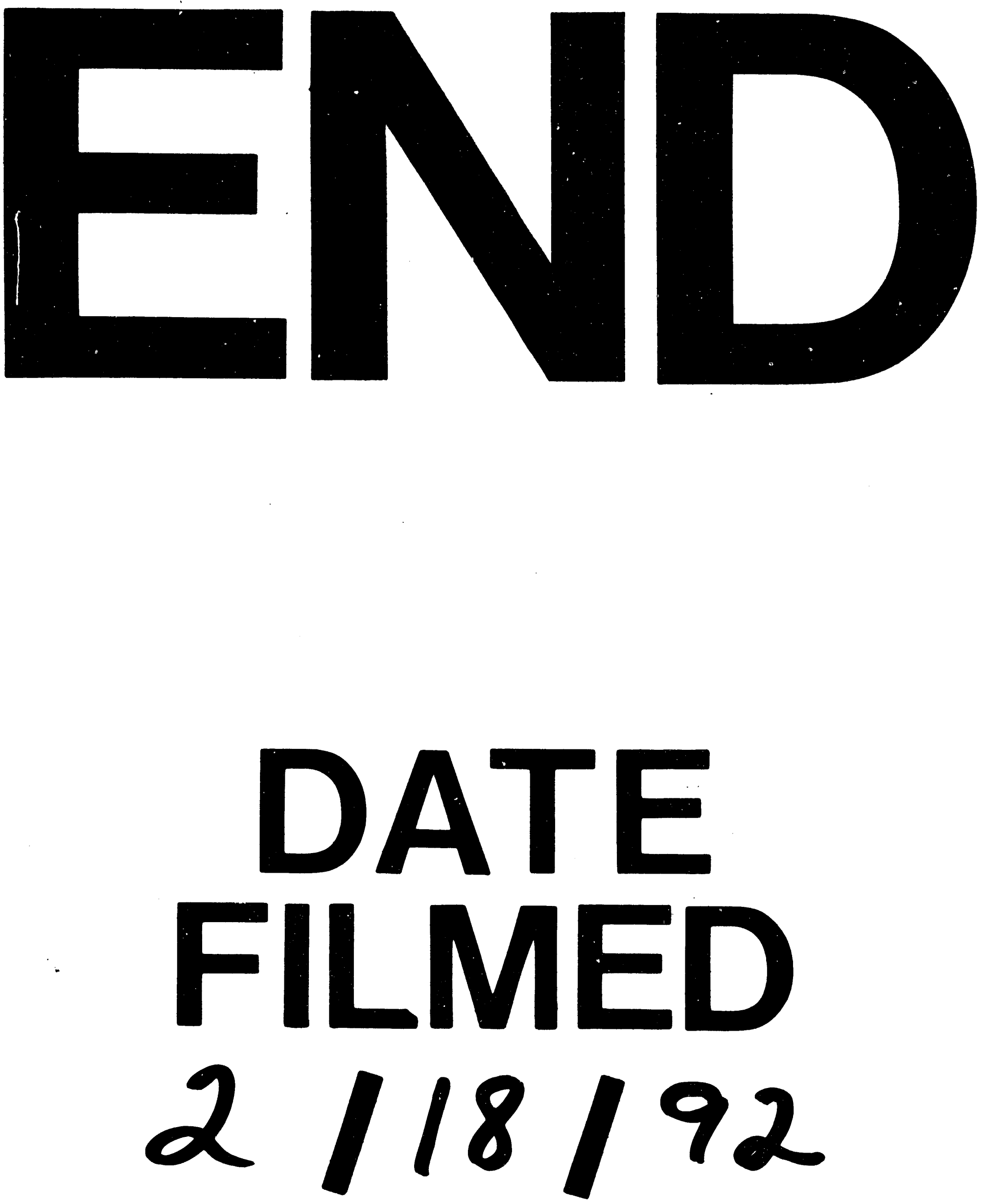

1 
